\title{
PENDEKATAN BIOETIK TENTANG EUTANASIA
}

\author{
${ }^{1}$ Mutiara D. B. I. Wakiran \\ ${ }^{2}$ Djemi Ch. Tomuka \\ ${ }^{2}$ Erwin G. Kristanto
}

\author{
${ }^{1}$ Kandidat Skripsi Fakultas Kedokteran Universitas Sam Ratulangi Manado \\ ${ }^{2}$ Bagian Ilmu Kedokteran Forensik dan Medikolegal Fakultas Kedokteran \\ Universitas Sam Ratulangi Manado \\ Email: mutchannomotteiru@yahoo.com
}

\begin{abstract}
Generally, a patient desires a 'normal' death free from pain and fear which is called in medical terms: euthanasia. Nowadays, euthanasia is a dilemmatic issue among doctors. Medical ethics has become a broader consideration which has developed quite rapidly in the last three decades; therefore, ethical considerations have become major concerns in the medical profession. They are often found in conflict especially between a doctor and a patient, and these can not be solved by using the traditional rules of medical ethics. In such cases, the rules of law, depending on region or nation, can be enforced, so that the problem under discussion (euthanasia) can not be separated from the issues of the rights and obligations of the involved parties. The rapid development in medical science and biology creates more complex problems which can not be solved by long-standing medical ethics; therefore, bioethics has been developed in the expectation of providing more available and logical solutions.
\end{abstract}

Keywords: euthanasia, death, conflict.

\begin{abstract}
Abstrak: Kematian yang diidamkan oleh para penderita ialah kematian yang normal, jauh dari rasa sakit dan mengerikan yang dalam istilah medis disebut eutanasia. Eutanasia merupakan suatu persoalan yang dilematik baik di kalangan dokter. Etika telah menjadi suatu bagian dari dunia kedokteran yang cukup pesat perkembanganya dalam tiga dekade terakhir dan pertimbangan etika menjadi perhatian utama dalam pelaksanaan profesi kedokteran. Dalam profesi ini seringkali dijumpai konflik antara dokter dan pasien yang tidak dapat dipecahkan oleh kaidah-kaidah etika. Dalam hal seperti ini maka kaidah-kaidah hukum dapat dapat diberlakukan, sehingga pembicaraan tidak dapat dilepaskan dari masalah hak dan kewajiban dari pihak-pihak yang yang terlibat dalam permasalahan tersebut. Perkembangan yang pesat dalam ilmu kedokteran dan biologi serta permasalahan yang mengiringinya semakin kompleks sehingga kajian tentang etika kedokteran yang membahas mengenai bidang medis dan profesi kedokteran saja tidak cukup; untuk itu dikembangkan bioetika (etika biomedis) yang diharapkan dapat menghasilkan solusi yang lebih dapat diterima dan logik.
\end{abstract}

Kata kunci: euthanasia, etika, konflik.

Kematian yang diidamkan oleh setiap individu ialah kematian yang normal tanpa disertai rasa sakit dan hal yang mengerikan. Dalam istilah medis, kematian demikian disebut euthanasia. ${ }^{1}$ Etika telah menjadi bagian dari dunia kedokteran yang berkembang cukup pesat dalam tiga dekade terakhir dan pertimbangan etika telah menjadi perhatian utama dalam pelaksanaan profesi kedokteran.

Dalam profesi kedokteran sering dijumpai konflik antara dokter dan pasien yang tidak dapat diselesaikan oleh kaidahkaidah etika. Dalam hal seperti ini maka 
kaidah-kaidah hukum dapat diberlakukan, sehingga pembicaraan tidak dapat dilepaskan dari masalah hak dan kewajiban dari pihak-pihak yang yang terlibat dalam permasalahan tersebut. ${ }^{2}$

\section{KEMATIAN DAN EUTANASIA}

\section{Eutanasia}

Kematian bagi sebagian besar umat manusia merupakan suatu hal yang tidak menyenangkan dan mungkin tidak dikehendaki sehingga manusia terus menerus tetap berusaha menunda untuk kematian dengan berbagai cara sejalan dengan kemajuan teknologi. Adanya penemuanpenemuan teknologi modern berdampak terjadinya perubahan-perubahan yang sangat cepat di dalam kehidupan sosial budaya; salah satu kemajuan teknologi itu di dalam bidang medis.

Istilah euthanasia berasal dari bahasa Yunani; "Eu" berarti baik dan "Thanatos" berarti mati. Dengan demikian, istilah Euthanasia dapat diartikan "mati dengan baik". ${ }^{3}$ Istilah tersebut hampir sama dengan pendapat Djoko Prakoso yang mendefinisikan euthanasia sebagai "mati dengan tenang" atau "a good death". 4

\section{Proses kematian}

Secara umum, proses kematian itu memiliki banyak istilah, antara lain: ${ }^{4}$

1. Orthothanasia, yaitu suatu kematian yang terjadi karena suatu proses alamiah.

2. Dysthanasia, yaitu suatu kematian yang terjadi secara tidak wajar.

3. Euthanasia, yaitu suatu kematian yang terjadi dengan pertolongan atau tidak dengan pertolongan dokter

\section{Jenis eutanasia}

Ditinjau dari cara pelaksanaan, eutanasia dapat dibedakan atas eutanasia pasif (mencabut segala tindakan/pengobatan) dan eutanasia aktif (intervensi aktif).

Eutanasia aktif ini dapat pula dibedakan atas eutanasia aktif langsung (direct) dan eutanasia aktif tidak langsung (indirect).

Ditinjau dari permintaan, eutanasia dapat dibedakan atas eutanasia voluntir/ sukarela yaitu atas permintaan pasien dan eutanasia involuntir yang tidak atas permintaan pasien. ${ }^{6}$

\section{Eutanasia dalam ketentuan perundang- undangan}

Dalam KUHP yang berkaitan dengan euthanasia yaitu KKUHP Bab XIX Kejahatan terhadap nyawa pasal 344, dapat dipaparkan sebagai berikut: ${ }^{8,9}$ BARANG SIAPA MERAMPAS NYAWA ORANG LAIN ATAS PERMINTAAN ORANG ITU SENDIRI YANG JELAS DINYATAKAN DENGAN KESUNGGUHAN HATI, DIANCAM DENGAN PIDANA PENJARA PALING LAMA DUA BELAS TAHUN.

Pasal di atas ini menghalangi para dokter untuk melakukan tindakan voluntary euthanasia. Bagi kalangan dokter yang berpegang pada pasal-pasal yang terdapat dalam KUHP, pelaksanaan eutanasia apapun jenisnya tidak mungkin dilaksanakan, terkecuali bila tindakan eutanasia tidak diartikan sebagai tindakan kejahatan sebagaimana dimaksudkan dalam KUHP.

\section{PENGERTIAN ETIKA}

Eutanasia saling berkaitan erat dengan etika sehingga banyak pendapat yang menyatakan bahwa perbuatan eutanasia tidak beretika. Istilah 'etika' berasal dari bahasa Yunani kuno yaitu bentuk tunggal kata 'etika' yaitu ethos sedangkan bentuk jamaknya yaitu ta etha. Ethos mempunyai banyak arti yaitu: tempat tinggal yang biasa, padang rumput, kandang, kebiasaan/adat, akhlak, watak, perasaan, sikap, dan cara berpikir; sedangkan arti ta etha yaitu adat kebiasaan. Dengan demikian etika mengacu pada nilai-nilai atau aturan yang berlaku dalam suatu kelompok manusia atau manusia perorangan. Melalui tinjauan etis, kita dapat menilai suatu tindakan atau perbuatan baik atau buruk. ${ }^{10}$ 


\section{Sejarah etika kedokteran}

Etika kedokteran mempunyai riwayat sejarah yang sama panjang dengan ilmu kedokteran itu sendiri. Bapak Ilmu Kedokteran yang berasal dari Yunani yaitu Hipocrates (460-377 BC) telah meletakkan dasar untuk etika kedokteran.

Pengamatan sejarah memperlihatkan bahwa kode etik pertama dalam bidang praktek medik telah dikeluarkan oleh bangsa yang hidup di lembah Mesopotamia (Babylon) sekitar 2500 tahun sebelum masehi. ${ }^{9}$

\section{Prinsip-prinsip etik}

Beauchamp and Childress (1994) mengemukakan bahwa untuk mencapai suatu keputusan etik diperlukan empat kaidah dasar moral dan beberapa aturan di bawahnya. Keempat kaidah dasar moral tersebut ialah: ${ }^{10}$

1. Prinsip otonomi, yaitu prinsip moral yang menghormati hak-hak pasien, terutama hak otonomi pasien. Prinsip moral inilah yang kemudian melahirkan doktrin informed consent. Dalam hal ini, seorang dokter wajib menghormati martabat dan hak manusia.

2. Prinsip beneficience, yaitu prinsip moral yang mengutamakan tindakan yang ditujukan demi kebaikan pasien. Dalam prisnip beneficience tidak hanya dikenal perbuatan untuk kebaikan saja, tetapi juga perbuatan dengan sisi baik yang lebih besar daripada sisi buruk. Dalam hal ini, seorang dokter harus berbuat baik, menghormati martabat manusia, dan dokter tersebut harus berusaha secara maksimal agar pasiennya tetap dalam kondisi sehat.

3. Prinsip non-malficience, yaitu prinsip moral yang melarang tindakan yang memperburuk keadaan pasien. Prinsip ini terkenal sebagai primum non nocere atau "above all do no harm". Nonmalficience ialah suatu prinsip dimana seorang dokter tidak melakukan perbuatan yang memperburuk pasien dan memilih pengobatan yang berisiko paling kecil bagi pasien yang dirawat atau diobati olehnya.

4. Prinsip justice, yaitu prinsip moral yang mementingkan fairness dan keadilan dalam bersikap maupun dalam mendistribusikan sumber daya. Keadilan (justice) merupakan suatu prinsip dimana seorang dokter wajib memberikan perlakuan sama rata serta adil untuk kebahagiaan dan kenyamanan pasien tersebut.

\section{Bioetika}

Menurut Kusumaatmaja, hukum sebagai kaidah sosial tidak terlepas dari nilai (values) yang berlaku di suatu masyarakat; bahkan dikatakan bahwa hukum itu merupakan pencerminan dari pada nilai-nilai yang berlaku dalam masyarakat. Abel merumuskan definisi tentang bioetika yang diterjemahkan Bertens sebagai berikut: Bioetika adalah studi interdisipliner tentang problemproblem yang ditimbulkan oleh perkembangan di bidang biologi dan ilmu kedokteran baik pada skala mikro maupun pada skala makro, lagipula tentang dampaknya atas masyarakat luas serta sistim nilainya kini dan masa mendatang. Bioetika bersifat pluralistik/terbuka karena pada bioetika kebudayaan dikedepankan, agamawan didengar, suara-suara yang berbeda direspon, dan dialog yang rasional dibuka. Bioetika (Biomedical ethics) merupakan cabang dari etika normatif dan merupakan etika yang berhubungan dengan praktek kedokteran dan atau penelitian dibidang biomedik. ${ }^{8}$

\section{BIOETIK DAN EUTANASIA}

Untuk meliput lebih jauh eutanasia dari segi bioetika, maka terlebih dahulu dikonstruksikan unsur dan ciri bioetika secara mendalam. Menurut Prof. Dr. Ir. Tien R. Muchtadi, MS dari Komisi Bioetika Nasional Deputi Bidang Pengembangan Sistem Iptek Nasional, bioetika terkait dengan kegiatan yang mencari jawaban dan menawarkan pemecahan 
masalah dari konflik moral. Konflik moral yang dimaksud meliputi konflik yang timbul dari kemajuan pesat ilmu-ilmu pengetahuan hayati dan kedok-teran, yang diikuti oleh penerapan teknologi yang terkait dengannya. Dalam hal ini, bioetika dapat pula dilihat sebagai cabang ilmu pengetahuan tersendiri yang berkenaan dengan konflik tersebut. ${ }^{11}$

Hipocrates menuangkan pemikiran mengenai eutanasia di dalam buku karyanya, antara lain Prognosis. Berg mengutip pandangan Hipocrates mengenai kematian pasien akibat penyakit yang tidak dapat disembuhkan. ${ }^{12}$ Dalam buku Medicine: The Forgotten Art, Elliot-Bijnns mengutip pandangan Hipocrates yang relevan dengan hal di atas, yaitu: Ilmu kedokteran adalah upaya mengurangi penderitaan si sakit, menyingkirkan penyakit, dan tidak mengobati kasus-kasus yang tidak memerlukan pengobatan. ${ }^{13}$

Berdasarkan kedua pandangan Hipocrates tersebut di atas dapat disimpulkan bahwa dokter tidak lagi mengobati penyakit-penyakit yang sebenarnya tidak perlu diobati atau tidak membohongi pasien yang sebenarnya sudah tidak memerlukan obat. Disamping itu, dokter itu tidak harus berupaya mengobati penyakit-penyakit yang tidak dapat disembuhkan lagi yaitu bila pengobatan atau perawatan dokter sudah tidak kompeten lagi untuk melakukan medikasi terhadap pasiennya. Pandangan lain dari Hipocrates yang dikutip oleh Elliot-Bijnns, ialah: 'Adalah gila untuk menuntut dari dokter upaya penyembuhan yang tidak dimungkinkan oleh ilmu kedokteran, seperti menuntut agar tubuh melawan penyakit yang sudah tidak dapat dihindarkannya'. ${ }^{12}$

Berdasarkan kutipan-kutipan tersebut di atas, dapat disimpulkan bahwa Hipocrates telah menerima eutanasia pasif, khususnya terhadap penyakit-penyakit yang tidak dapat disembuhkan lagi, sedangkan mengenai eutanasia aktif, salah satu sumpah Hipocrates berbunyi: "Saya tidak akan memberikan obat yang mematikan kepada siapa pun meskipun dimintanya, atau menganjurkan kepada mereka untuk tujuan itu". ${ }^{33}$ Sumpah Hipocrates tersebut menunjukkan bahwa dalam situasi apapun keadaan pasien, Hipocrates tidak akan memberikan obat yang mematikan sekalipun pasien telah memintanya; dengan kata lain, Hipocrates tetap menolak tindakan eutanasia aktif. Dokter lebih baik memberikan penjelasan terhadap pasiennya untuk memahami kenyataan yang sedang dihadapinya, yaitu pada saat-saat menjelang kematiannya. Jadi, menurut Hipocrates tindakan eutanasia aktif merupakan perbuatan yang dilarang, sedangkan untuk penyakit-penyakit yang yang tidak dapat disembuhkan lagi, lebih baik melakukan eutanasia pasif. ${ }^{15}$

Tugas seorang dokter ialah untuk menolong jiwa seorang pasien, walaupun bila hal tersebut sudah tidak bisa dilanjutkan lagi dan bila diteruskan, kadangkadang malah akan menambah penderitaan seorang pasien. Penghentian pertolongan tersebut merupakan salah satu bentuk eutanasia. Dalam KODEKI pasal 2 dijelaskan bahwa; "seorang dokter harus senantiasa berupaya melaksanakan profesinya sesuai dengan standar profesi tertinggi". Jelasnya, seorang dokter dalam melakukan kegiatan kedokterannya sebagai seorang profesi dokter harus sesuai dengan ilmu kedokteran mutakhir, hukum, dan agama. Berdasarkan perspektif kesehatan maka eutanasia masih tidak diperbolehkan karena pada dasarnya dokter harus tetap bersikap profesional dan mengupayakan semaksimal mungkin untuk pengobatan pasien. Menurut KODEKI dokter juga tidak boleh tidak mengupayakan atau melakukan pembiaran terhadap penderitaan pasien. $^{15}$

Bertolak dari ketentuan Pasal 344 KUHP tersimpul bahwa pembunuhan atas permintaan korban sekalipun tetap diancam pidana bagi pelakunya. Dengan demikian, dalam konteks hukum positif di Indonesia, eutanasia tetap dianggap sebagai perbuatan yang dilarang dan tidak dimungkinkan melakukan pengakhiran hidup seseorang sekalipun atas permintaan orang itu sendiri. Perbuatan tersebut tetap dikualifikasi sebagai tindak pidana, yaitu sebagai 
perbuatan yang diancam dengan pidana bagi siapa yang melanggar larangan tersebut.

Tiap jenis eutanasia mengandung aspek moral dan etika yang harus menjadi pertimbangan mendalam, mengingat penentuan hidup dan mati tidak ditangan manusia semata. Bila kita melihat lebih jauh mengenai hak-hak pasien untuk menentukan nasib sendiri, eutanasia nampak sebagai pilihan cerdas untuk mengakhiri penderitaan karena pasien tidak berkeberatan hidupnya berakhir (eutanasia sukarela). Walaupun demikian, penghargaan atas nilai insani ini tidak begitu saja dapat diabaikan meskipun oleh si pemilik jiwa itu sendiri yaitu pasien, oleh karena hal tersebut akan membuka peluang bagi yang lain untuk mengakhiri hidupnya dengan begitu mudah bila ia tidak lagi mampu menahan penderitaan. Terlebih lagi bagi pasien yang sudah berada dalam kondisi koma selama bertahun-tahun, faktor biaya, perawatan, dan faktor mental spiritual menjadi harga yang begitu mahal harus dibayar untuk mempertahankan kehidupan seseorang tanpa mengetahui apakah harapan itu masih ada. $^{15}$

\section{Bioetik, eutanasia, dan keterkaitannya dengan agama}

Pandangan Bioetika merupakan hal yang interdisiplin, dengan melibatkan ilmu biomedik, hukum, ilmu sosial, teologi, dan lainnya. Umumnya agama tidak membenarkan tindakan eutanasia. Syariah Islam mengharamkan eutanasia aktif, karena termasuk dalam kategori pembunuhan sengaja (al-qatlu al-'amad). Pandangan agama Hindu terhadap eutanasia mengungkapkan bahwa bunuh diri ialah suatu perbuatan yang terlarang di dalam ajaran Hindu dengan pemikiran bahwa perbuatan tersebut dapat menjadi suatu faktor yang mengganggu pada saat reinkarnasi oleh karena menghasilkan "karma" buruk. Eutanasia atau mercy killing baik yang aktif atau pasif tidak dibenarkan dalam agama Buddha karena perbuatan membunuh atau mengakhiri kehidupan seseorang ini, walaupun dengan alasan kasih sayang, tetap melanggar sila pertama dari Pancasila Buddhis. Gereja Katolik telah berjuang untuk memberikan pedoman sejelas mungkin mengenai penanganan terhadap mereka yang menderita sakit tak tersembuhkan, sehubungan dengan ajaran moral gereja mengenai eutanasia dan sistem penunjang hidup. $^{14}$

Apapun alasan untuk eutanasia pasti memerlukan jawaban yang tidak mudah, apalagi bagi setiap orang yang memiliki agama tertentu dan meyakini keajaiban Tuhan. Namun secara manusiawi, setiap orang pasti dihadapkan pada pilihan-pilihan yang dianggap terbaik bagi semua.

Pada setiap situasi yang dihadapi, seseorang akan diperhadapkan dengan dilema etik untuk mengambi keputusan mengenai perilaku yang layak dan yang harus diambil. Dengan mengacu pada berbagai pandangan di atas, ditinjau dari sudut pandang Bioetika eutanasia merupakan suatu hal yang tidak etik; perbuatan mengakhiri hidup manusia tetap tidak bermoral dan juga melanggar hukum Tuhan. ${ }^{14}$

\section{SIMPULAN}

Eutanasia merupakan salah satu masalah moral yang dihadapi dewasa ini, yang membutuhkan penyelesaian yang komperhensif dari berbagai pihak. Secara umum, eutanasia berkaitan erat dengan norma-norma sosial lainnya, yaitu norma agama, hak asasi manusia, dan etika kedokteran.

Di Indonesia, eutanasia merupakan perbuatan yang melanggar Kode Etik Kedokteran Indonesia. perbuatan yang tidak beretika, amoral, bahkan melanggar hukum. Dari aspek norma hukum terutama hukum pidana, pengaturan eutanasia berhubungan erat dengan kepentingan perseorangan menyangkut perlindungan terhadap nyawa seseorang.

\section{UCAPAN TERIMA KASIH}

Ucapan terima kasih ditujukan kepada dr. L. Ratulangi, Sp.F dan dr. Johannis F. 
Mallo SH, Sp.F, DFM, DK selaku penguji skripsi, dan pada semua pihak baik secara langsung atau tidak langsung telah menumbuhkan ide dan gagasan pada penulis.

\section{DAFTAR PUSTAKA}

1. Aseri FA. Euthanasia suatu tinjauan dari segi Kedokteran Hukum Pidana dan Hukum Islam. In: Problematika Hukum Kontemporer. Jakarta: Pustaka Firdaus; 1995.

2. Bertens K. Keprihatinan Moral. Yogyakarta: Kanisius; 2003.

3. Gunawan. Memahami Etika Kedokteran. Yogyakarta: Kanisius; 1992.

4. Prakoso D, Nirwanto DA. Euthanasia, Hak Asasi Manusia dan Hukum Pidana. Jakarta: Ghalia Indonesia; 1984.

5. Dewi AI. Etika dan Hukum Kesehatan. Yogyakarta: Pustaka Book Publisher; 2008.

6. Hanafiah M. Etika Kedokteran dan Hukum Kesehatan. Jakarta: Buku Kedokteran EGC; 1999.

7. Hanafiah M, Amir A. Etika Kedokteran dan Hukum Kesehatan. Jakarta: Buku Kedokteran EGC; 2007.

8. William JR. Medical Ethics Manual. Yogyakarta: Pusat Studi Kedokteran
Islam Fakultas Kedokteran UMY. 2002.

9. Samil RS. Etika Kedokteran Indonesia. Jakarta: Yayasan Bina Pustaka Sarwono Prawirohardjo; 2001.

10. Sampurna B, Syamsu Z, Dwidja T. Bioetik dan Hukum Kedokteran: Etik pada akhir kehidupan. Jakarta: Pustaka Dwipar; 2007.

11. Muchtadi TR. Perkembangan Bioetika Nasional. Seminar Etika Penelitian di Bidang Kesehatan Reproduksi. Surabaya: Fakultas Kedokteran Universitas Airlangga; 2007.

12. Kartono M. Euthanasia dipandang dari Etika Kedokteran. Jakarta: Sinar Harapan; 1984.

13. Soekanto S, Kartono M. Aspek Hukum dan Etika Kedokteran di Indonesia. Jakarta: Grafiti Pers, 1983.

14. Hidayat G. Pandangan 5 agama terhadap Euthanasia [homepage on the Internet]. 2010 [cited 2012 Nov 10]. Available from: http://gustihidayatullah.blogspot. com/2010/11/pandangan-5-agama-ter hadap. html.

15. Wibowo K. Euthanasia dan Bioetika [homepage on the Internet]. 2011. [cited 2012 Nov 10]. Available from: http://pengacaraonlinecom.blogspot.co $\mathrm{m} / 2011 / 11 /$ euthanasia-dan-bioetika. html. 